\title{
Selective Monohydrocyanation of Diimine using Potassium Hexacyanoferrate(II)-Benzoyl Chloride Reagent System as a Cyanide Source
}

\author{
ZHENG LI*, FEI WEN and JINGYA YANG \\ College of Chemistry and Chemical Engineering, Northwest Normal University, Lanzhou, \\ Gansu 730070, P. R. China \\ e-mail: lizheng@nwnu.edu.cn
}

MS received 22 June 2016; revised 26 August 2016; accepted 12 September 2016

\begin{abstract}
The selective monohydrocyanation of diimines using potassium hexacyanoferrate(II)-benzoyl chloride reagent system as a cyanide source under catalyst-free condition is described. The advantages of this protocol are the non-toxic, non-volatile and inexpensive cyanide source, high yield, and simple work-up procedure.
\end{abstract}

Keywords. Aminonitrile; monohydrocyanation; diamine; potassium hexacyanoferrate(II)

\section{Introduction}

Nucleophilic addition of cyanide to imine is an important way to access $\alpha$-aminonitriles. ${ }^{1} \alpha$-Aminonitriles are very useful building blocks in the construction of a variety of organic intermediates, such as natural and unnatural $\alpha$-amino acids, ${ }^{2}$ different nitrogen-containing heterocycles like imidazoles, ${ }^{3}$ thiadiazoles. ${ }^{4}$ Over the past decade, lots of synthetic protocols for the preparation of $\alpha$-aminonitriles have been reported. The direct introduction of cyano groups into molecules which contain unsaturated carbon-nitrogen bonds appears to be one of the most straightforward methods. However, some of these approaches use strongly toxic chemicals, such as $\mathrm{HCN},{ }^{5} \mathrm{NaCN}^{6}$ and $\mathrm{KCN},{ }^{7}$ as cyanating agents, which render nucleophilic additions unsafe and environmentally unfriendly. Recently, some safer cyanating agents, such as $\mathrm{Zn}(\mathrm{CN})_{2},{ }^{8} \mathrm{TMSCN}^{9}$ and acetone cyanohydrin, ${ }^{10}$ were also reported. However, the exploration for green cyanide sources still has very important meaning to the environment.

Potassium hexacyanoferrate(II), $\mathrm{K}_{4}\left[\mathrm{Fe}(\mathrm{CN})_{6}\right]$, is a byproduct of the coal chemical industry and commercially available on a ton scale. It is also used in the food industry for metal precipitation. In addition, it has been described as an anti-agglutinating auxiliary for table salt $(\mathrm{NaCl})$. Recently, $\mathrm{K}_{4}\left[\mathrm{Fe}(\mathrm{CN})_{6}\right]$ has been used as a cyanide source for some substitution reactions to

*For correspondence synthesize benzonitriles, ${ }^{11-14}$ aroyl cyanides,${ }^{15}$ sulfonyl cyanides, ${ }^{16}$ benzyl cyanides,${ }^{17}$ and cinnamonitriles. ${ }^{18}$ Our current research interests focused on the cyanation of unsaturated compounds including $\mathrm{C}=\mathrm{O}, \mathrm{C}=\mathrm{N}$ and/or $\mathrm{C}=\mathrm{C}$ bonds by nucleophilic addition reactions using $\mathrm{K}_{4}\left[\mathrm{Fe}(\mathrm{CN})_{6}\right]$ as a cyanide source. ${ }^{19-24}$ Especially, our research group recently has reported some examples for the hydrocyanation of enones, ${ }^{25-28}$ imines, ${ }^{29-31}$ unsaturated esters ${ }^{32}$ and unsaturated nitriles ${ }^{33}$ by using $\mathrm{K}_{4}\left[\mathrm{Fe}(\mathrm{CN})_{6}\right]$ as a cyanide source. As an extension, in this work, we report an efficient method for the selective monohydrocyanation of substrates bearing two $\mathrm{C}=\mathrm{N}$ bonds, diimines, using $\mathrm{K}_{4}\left[\mathrm{Fe}(\mathrm{CN})_{6}\right]$-benzoyl chloride reagent system as a cyanide source under catalyst-free condition.

\section{Experimental}

\subsection{General information}

IR spectra were recorded using $\mathrm{KBr}$ pellets on an Alpha Centauri FTIR spectrophotometer. ${ }^{1} \mathrm{H}$ NMR and ${ }^{13} \mathrm{C}$ NMR spectra were recorded on a Mercury-400BB instrument using $\mathrm{CDCl}_{3}$ as solvent and $\mathrm{Me}_{4} \mathrm{Si}$ as internal standard. Elemental analyses were performed on a Vario El Elemental Analysis instrument. Melting points were observed in an electrothermal melting point apparatus. Potassium hexacyanoferrate(II) was dried at $80^{\circ} \mathrm{C}$ under vacuum for $24 \mathrm{~h}$ and finely powdered prior to use. Diimines were prepared according to literature procedure. $^{34}$ 


\subsection{The general procedure for the monohydrocyanation of diimines}

The mixture of $\mathrm{K}_{4}\left[\mathrm{Fe}(\mathrm{CN})_{6}\right](0.2 \mathrm{mmol})$ and benzoyl chloride $(1.2 \mathrm{mmol})$ was heated at $160^{\circ} \mathrm{C}$ for $3 \mathrm{~h}$, then the reaction system was cooled to room temperature and diimine $(1 \mathrm{mmol})$ in $20 \mathrm{~mL}$ of $\mathrm{MeOH}$ was added. The mixture was stirred at room temperature for appropriate times indicated in Table 2. After completion of the reaction monitored by TLC, the resulting mixture was filtered, and the filtrate was concentrated under reduced pressure, and the residue was isolated by column chromatography using petroleum ether and ethyl acetate as an eluent to obtain pure product.

\section{Results and Discussion}

Previous work in our group showed that $\mathrm{K}_{4}\left[\mathrm{Fe}(\mathrm{CN})_{6}\right]$ can abstract cyanide ions when using an efficient promoter without transition metal catalysts. It was found that benzoyl chloride could efficiently promote $\mathrm{K}_{4}\left[\mathrm{Fe}(\mathrm{CN})_{6}\right]$ to release cyanide ions and yield an intermediate, benzoyl cyanide, which could be identified and isolated from the reaction system. ${ }^{35}$ In this paper, we focus on the hydrocyanation of diimines with $\mathrm{K}_{4}\left[\mathrm{Fe}(\mathrm{CN})_{6}\right]$ by a one-pot two-step procedure using benzoyl chloride as a promoter.

Initially, $N, N^{\prime}$-diphenylbutane-2,3-diimine (1a) ( Scheme $1, \mathrm{R}^{1}=\mathrm{Ph}, \mathrm{R}^{2}=\mathrm{Me}$ ) was selected as a substrate to examine the feasibility of hydrocyantion with $\mathrm{K}_{4}\left[\mathrm{Fe}(\mathrm{CN})_{6}\right]$. It was found that 1a could be hydrocyanated smoothly under catalyst-free condition to afford 2-methyl-2-(phenylamino)-3-(phenylimino)butanenitrile (2a) as sole product in 91\% yield only using benzoyl chloride as a promoter. This reaction was even conducted using bases, acids or transition metal complexes as catalysts. However, no improved yield was observed. In this reaction, it was found that for $1 \mathrm{~mol}$ of $\mathbf{1 a}$, only 0.2 equiv. of $\mathrm{K}_{4}\left[\mathrm{Fe}(\mathrm{CN})_{6}\right]$ was required, which indicated that all six $\mathrm{CN}^{-}$groups in $\mathrm{K}_{4}\left[\mathrm{Fe}(\mathrm{CN})_{6}\right]$ could be readily utilized in this reaction. However, the dihydrocyanated product was not observed under the studied conditions. This result indicates the high monohydrocyanating selectivity of $\mathbf{1 a}$ to $\mathbf{2 a}$.

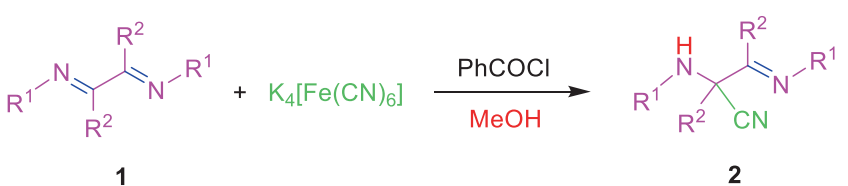

Scheme 1. Selective monohydrocyanation of diimines with $\mathrm{K}_{4}\left[\mathrm{Fe}(\mathrm{CN})_{6}\right]$.
In order to further confirm the possibility of dihydrocyantion, the isolated product $\mathbf{2 a}$ was further reacted with $\mathrm{K}_{4}\left[\mathrm{Fe}(\mathrm{CN})_{6}\right]$-benzoyl chloride reagent system under similar condition, including the use of an excess amount of $\mathrm{K}_{4}\left[\mathrm{Fe}(\mathrm{CN})_{6}\right]$, prolonged reaction time and elevated reaction temperature (Scheme 2). However, no dihydrocyanated product was obtained. This result further demonstrated the monohydrocyanation selectivity of 1a. The possible reason is that steric hindrance of monohydracyanated product $\mathbf{2 a}$ efficiently blocked further hydrocyanation of the second $\mathrm{C}=\mathrm{N}$ bond of $\mathbf{2 a}$ with $\mathrm{K}_{4}\left[\mathrm{Fe}(\mathrm{CN})_{6}\right]$.

The solvent also played an important role in this reaction. It was found that the model reaction in toluene could not take place (Table 1 , entry 1 ). The reaction in THF, 1,4-dioxane, $\mathrm{CH}_{2} \mathrm{Cl}_{2}, \mathrm{MeCN}$, DMSO and $\mathrm{DMF}$ could give the desired product in moderate yield (Table 1, entries 2-7). In contrast, the reaction in $\mathrm{MeOH}$ and $\mathrm{EtOH}$ afforded the desired product in high yield (Table 1, entries 8-9). Among them, $\mathrm{MeOH}$ was the best solvent for the reaction (Table 1, entry 8 ).

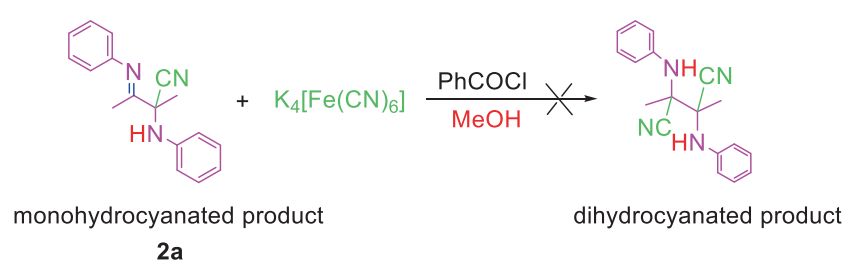

Scheme 2. Further hydrocyanation of monohydrocyanated product $\mathbf{2 a}$.

Table 1. The effect of solvents on the yield of the monohydrocyanation of $\mathbf{1 a}$ with $\mathrm{K}_{4}\left[\mathrm{Fe}(\mathrm{CN})_{6}\right]^{a}$.

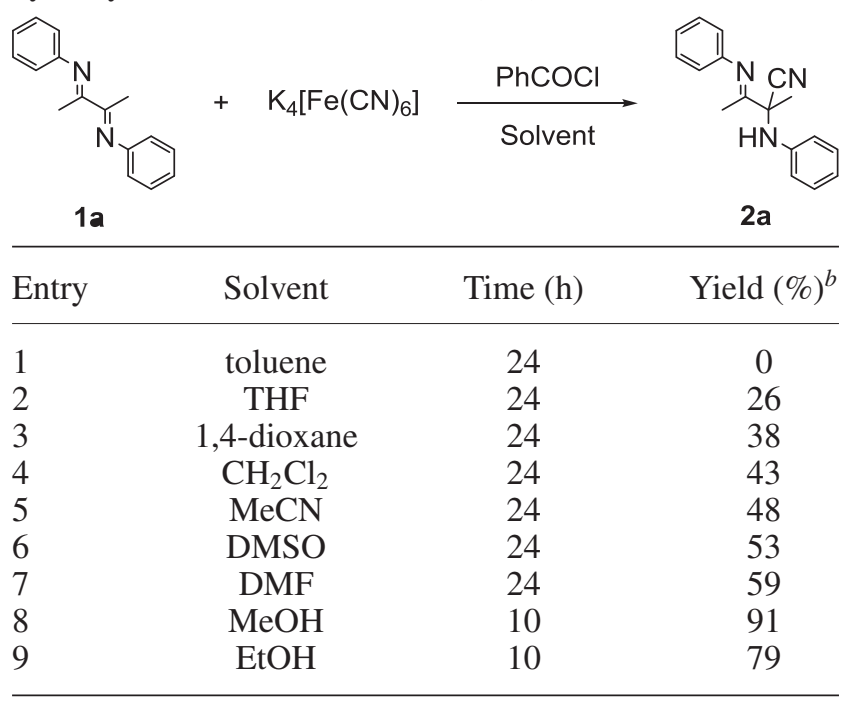

${ }^{a}$ Reaction condition: 1a $(1 \mathrm{mmol})$, potassium hexacyanoferrate(II) $(0.2 \mathrm{mmol})$, benzoyl chloride $(1.2 \mathrm{mmol})$ in $20 \mathrm{~mL}$ of solvent.

${ }^{b}$ Isolated yields. 
Table 2. Monohydrocyanation of diimines with $\mathrm{K}_{4}\left[\mathrm{Fe}(\mathrm{CN})_{6}\right]$-benzoyl chloride reagent system $^{a}$.

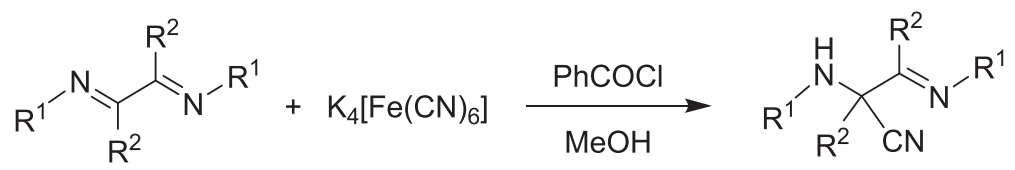

1

2

\begin{tabular}{lllll}
\hline Entry & $\mathrm{R}^{1}$ & $\mathrm{R}^{2}$ & Product & Time (h) \\
\hline
\end{tabular}

1

$\mathrm{C}_{6} \mathrm{H}_{5}$

$\mathrm{CH}_{3}$

$2 \mathbf{a}$

10

91

2

2- $\mathrm{CH}_{3} \mathrm{C}_{6} \mathrm{H}_{4}$

$\mathrm{CH}_{3}$

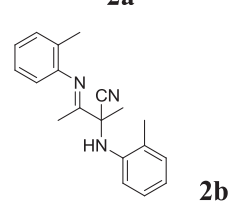

12

87

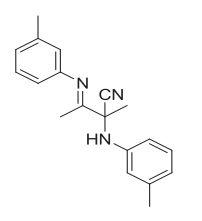

3

3- $\mathrm{CH}_{3} \mathrm{C}_{6} \mathrm{H}_{4}$

$\mathrm{CH}_{3}$

2c

12

89

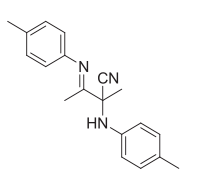

4

4- $\mathrm{CH}_{3} \mathrm{C}_{6} \mathrm{H}_{4}$

$\mathrm{CH}_{3}$

2d

10

98

5

2,3- $-\left(\mathrm{CH}_{3}\right)_{2} \mathrm{C}_{6} \mathrm{H}_{3}$

$\mathrm{CH}_{3}$

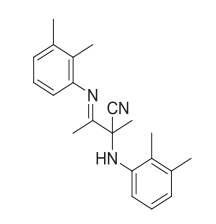

$2,3-\left(\mathrm{CH}_{3}\right)_{2} \mathrm{C}_{6} \mathrm{H}_{3}-\mathrm{CH}_{3}$

$2 \mathrm{e}$

83

6

2,3- $-\left(\mathrm{CH}_{3}\right)_{2} \mathrm{C}_{6} \mathrm{H}_{3}$

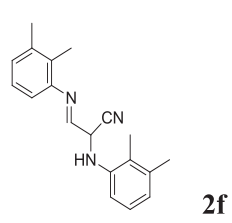

12

7

2,4- $\left(\mathrm{CH}_{3}\right)_{2} \mathrm{C}_{6} \mathrm{H}_{3}$

$\mathrm{H}$

$2 \mathrm{~g}$

12

87

8

2- $\mathrm{CH}_{3} \mathrm{OC}_{6} \mathrm{H}_{4}$

$\mathrm{H}$

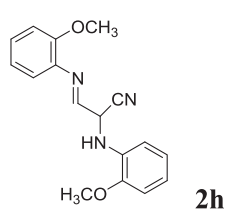

12

89

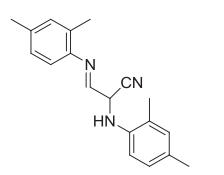

12 
Table 2. Continued.

Entry

${ }^{a}$ Reaction conditions: diimine $(1 \mathrm{mmol}), \mathrm{K}_{4}\left[\mathrm{Fe}(\mathrm{CN})_{6}\right](0.2 \mathrm{mmol})$, benzoyl chloride $(1.2$ $\mathrm{mmol}), \mathrm{MeOH}(20 \mathrm{~mL})$.

${ }^{b}$ Isolated yield.

Based on the above findings, a series of diimines $\mathbf{1}$ were used as substrates to conduct the monohydrocyanation in $\mathrm{MeOH}$ with $\mathrm{K}_{4}\left[\mathrm{Fe}(\mathrm{CN})_{6}\right]$-benzoyl chloride reagent system as a cyanide source under catalystfree conditions (Scheme 1 and Table 2). Diimines 1 with electron-donating groups on the aromatic rings of $\mathrm{R}^{1}$ afforded the products in slightly higher yield than diimines 1 with electron-withdrawing groups. In addition, diimines $\mathbf{1}$ bearing ortho-substituted aromatic rings could give slightly lower yields than the meta- and para-substituted analogues because of the large steric hindrance. The monohydrocyanation of unsymmetrical diimines was also investigated under similar conditions. However, complex mixtures were observed for each substrate. This indicated that $\mathrm{R}^{1}$ and $\mathrm{R}^{2}$ groups had no selective effect on the monohydrocyanation.

A plausible mechanism for the monohydrocyanation of diimines using $\mathrm{K}_{4}\left[\mathrm{Fe}(\mathrm{CN})_{6}\right]$-benzoyl chloride reagent system as a cyanide source is shown in Scheme 3. First, $\mathrm{K}_{4}\left[\mathrm{Fe}(\mathrm{CN})_{6}\right]$ reacts with benzoyl chloride to form benzoyl cyanide as an intermediate, which was confirmed by its isolation and identification. Then, benzoyl cyanide is attacked by methanol to yield nucleophilic addition intermediate $\mathbf{A}$. Intermediate $\mathbf{A}$ undergoes the loss of methyl benzoate to produce hydrogen cyanide in situ. Nucleophilic additions of hydrogen cyanide to diimines $\mathbf{1}$ yield $\alpha$-aminonitriles $\mathbf{2}$ as final products. 


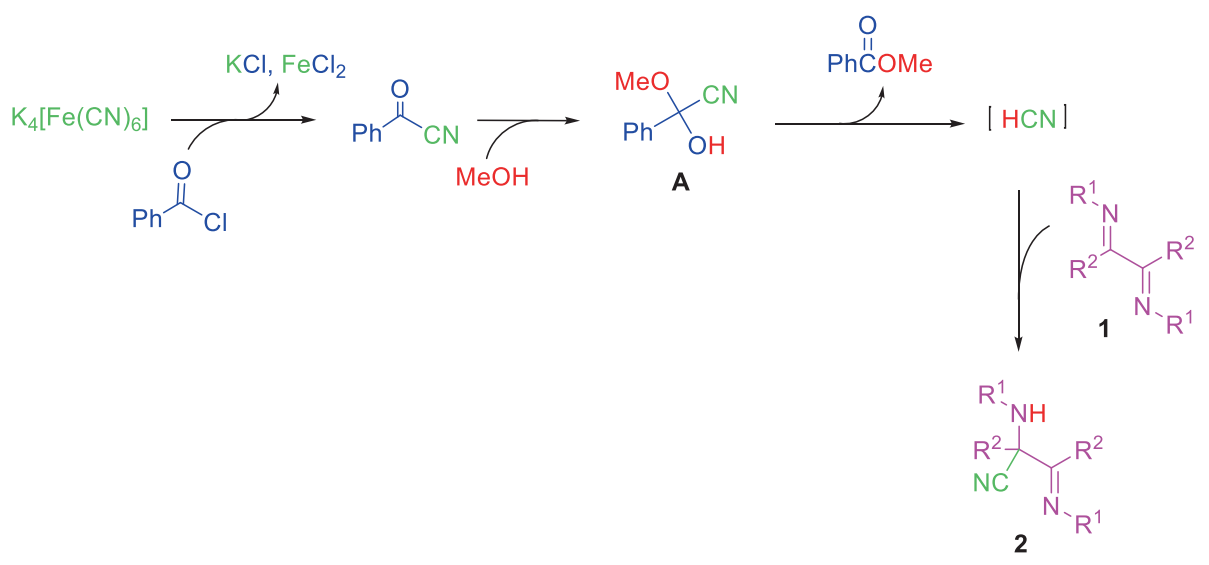

Scheme 3. The proposed mechanism for the monohydrocyanation of diimines with $\mathrm{K}_{4}\left[\mathrm{Fe}(\mathrm{CN})_{6}\right]$-benzoyl chloride reagent system.

\section{Conclusions}

In summary, an efficient method has been developed for the selective monohydrocyanation of diimines to synthesize $\alpha$-aminonitriles bearing $\mathrm{C}=\mathrm{N}$ bonds by onepot two-step procedure using $\mathrm{K}_{4}\left[\mathrm{Fe}(\mathrm{CN})_{6}\right]$ and benzoyl chloride reagent system as a cyanide source under transition metal catalyst-free condition. Non-toxic, nonvolatile and inexpensive cyanide source, high yield and simple work-up procedures are the advantages of this protocol.

\section{Supplementary Information (SI)}

Full set of characterization data (IR, ${ }^{1} \mathrm{H}$ and ${ }^{13} \mathrm{C}$ NMR spectra) and Figures S1-S39 are available at www.ias. ac.in/chemsci.

\section{Acknowledgements}

The authors thank the National Natural Science Foundation of China $(21462038,21362034)$ and Key Laboratory of Eco-Environment-Related Polymer Materials, Ministry of Education for the financial support of this work.

\section{References}

1. Royer L, De S K and Gibbs R A 2005 Tetrahedron Lett. 464595

2. Duthaler R O 1994 Tetrahedron 501539

3. Matier W L, Owens D A, Comer W T, Deitchman D, Ferguson H C, Seidehamel R J and Young J R 1973 J. Med. Chem. 16901

4. Weinstock L M, Davis P, Handelsman B and Tull R J 1967 J. Org. Chem. 322823

5. Corey E J and Grogan M J 1999 Org. Lett. 1157

6. Murahashi S, Nakae T, Terai H and Komiya N 2008 J. Am. Chem. Soc. 13011005

7. Ooi T, Uematsu Y and Maruoka K 2006 J. Am. Chem. Soc. 1282548
8. Marcantonio K M and Frey L F 2004 Org. Lett. 63723

9. Seayad A M and Chai C L L 2010 Org. Lett. 12264

10. Sakai T and Ukaji Y 2013 Org. Lett. 152422

11. Gerber R, Oberholzer M and Frech C M 2012 Chem. Eur. J. 182978

12. Yeung P Y, Tsang C P and Kwong F Y 2011 Tetrahedron Lett. $\mathbf{5 2} 7038$

13. Anbarasan P, Neumann H and Beller M 2011 Chem. Eur. J. 174217

14. Yueng P Y, Chau M S and Chak P L 2011 Org. Lett. 13648

15. Li Z, Shi S Y and Yang J Y 2006 Synlett 2495

16. Li Z and Xu J 2014 Phosphorus, Sulfur Silicon Relat. Elem. 189374

17. Ren Y L, Dong C H, Zhao S, Sun Y P, Wang J J, Ma J Y and Hou C D 2012 Tetrahedron Lett. 532825

18. Saha D, Adak L, Mukherjee M and Ranu B C 2012 Org. Biomol. Chem. 10952

19. Zhao Z X and Li Z 2010 Eur. J. Org. Chem. 5460

20. Zhao Z X and Li Z 2011 J. Braz. Chem. Soc. 22148

21. Hu X C, Zhao Z X and Li Z 2012 Phosphorus, Sulfur Silicon Relat. Elem. 1871003

22. Li Z, Li R Z, Zheng H H, Wen F, Li H B, Yin J J and Yang J Y 2013 J. Braz. Chem. Soc. 241739

23. Li Z, Niu P X, Li R Z, Zhang Y P, Ma B and Yang J Y 2012 J. Chem. Res. 36709

24. Li Z, Tian G Q and Ma Y H 2010 Synlett 2164

25. Li Z, Liu C H, Zhang Y P, Li R Z, Ma B and Yang J Y 2012 Synlett 232567

26. Li Z, Yin J J, Li T P, Wen G, Shen X L and Yang J Y 2014 Tetrahedron 705619

27. Li Z and Zheng H H 2014 Green Process Synth. 3447

28. Hu X N, Liu C H and Li Z 2015 J. Chem. Res. 3944

29. Hu X C, Ma Y H and Li Z 2012 J. Organomet. Chem. 70570

30. Hu X C, Li H B, Yang J Y and Li Z 2014 Synlett 251786

31. Li Z, Wen F and Yang J Y 2014 Chin. J. Chem. 321251

32. Li Z, Zhang Y P, Wen F, Yin J J, Zheng H H, Li H B and Yang J Y 2013 J. Chem. Res. 37601

33. Zhang Y P, Hu X C and Li Z 2015 Chem. Pap. 69596

34. Armesto D, Bosch P, Gallego H G, Martin J F, Ortiz H J, Perez-Ossorio R and Ramos A 1987 Org. Prep. Proced. Int. 19181

35. Li Z, Ma Y H, Xu J, Shi J H and Cai H F 2010 Tetrahedron Lett. $\mathbf{5 1} 3922$ 